\title{
Are the new Ediacaran Doushantuo embryo-like fossils early metazoans? A reply
}

Lei Chen ${ }^{\text {a }}$, Shuhai Xiao ${ }^{\text {b, } * \text {, Ke Pang }}{ }^{\text {c }}$, Chuan-Ming Zhou ${ }^{c}$, Xun-Lai Yuan ${ }^{\text {d }}$

${ }^{\text {a }}$ College of Earth Science and Engineering, Shandong University of Science and Technology, Qingdao, Shandong 266590, China

${ }^{\mathrm{b}}$ Department of Geosciences, Virginia Tech, Blacksburg, VA 24061, USA

${ }^{c}$ LESP, Nanjing Institute of Geology and Paleontology, Chinese Academy of Sciences, Nanjing 210008, China

${ }^{\mathrm{d}}$ LPS, Nanjing Institute of Geology and Paleontology, Chinese Academy of Sciences, Nanjing 210008, China

* Corresponding author at: Department of Geosciences, Virginia Tech, Blacksburg, VA 24061, USA. Tel.: +1 540-231-1366; fax: +1 540-231-3386; E-mail address: xiao@vt.edu

\begin{abstract}
Chen et al. (2014) described a suite of one-celled, Parapandorina-stage, Megaclonophycus-stage (some with dyads and tetrads), and matryoshka-stage fossils from the Doushantuo Formation, and interpreted them as representing a sequence of ontogenetic stages of the animal embryo-like fossil Megasphaera. Tang (2015) argues that the matryoshkas might have been parasites or symbionts, rather than developmental products of dyads and tetrads in Megaclonophycus-stage fossils. Assessing Tang's (2015) arguments against available evidence, we conclude that the matryoshkas likely represent an ontogenetic stage of Megasphaera. As such, they have the potential to illuminate the developmental biology, life cycle, and
\end{abstract}


phylogenetic affinity of the enigmatic fossil Megasphaera.

Keywords: Ediacaran Period; Doushantuo Formation; Megasphaera; Metazoan

We welcome Tang's (2015) comments on our interpretation of the animal embryo-like fossil Megasphaera from the Ediacaran Doushantuo Formation at Weng'an, South China (Chen et al., 2014). In his commentary, Tang first provides a review of the current controversies surrounding Megasphaera and related microfossils (Xiao et al., 2014a, 2014b), and then offers an "alternative" interpretation that Megasphaera might be an alga rather than a stem-group metazoan, although his "alternative" view is implied and not explicitly stated. Tang's "alternative" interpretation is based largely on the inference that the matryoshkas do not represent an ontogenetic stage of Megasphaera. Instead, Tang (2015) argues that the matryoshkas might have been parasites and symbionts that are phylogenetically afar from the host organisms of Megasphaera, thus refuting the ontogenetic sequence proposed by Chen et al. (2014) and questioning evidence for cell differentiation, soma-germ differentiation, and programmed cell death in Megasphaera.

It appears that Tang (2015) misunderstands Chen et al.’s (2014) scientific approach and major conclusion. Chen et al.'s (2014) scientific approach was to test and falsify hypotheses. This approach is commonly used in historical science, because it is difficult to prove specific historical scenarios. For example, it is almost impossible to prove that Cryogenian atmospheric $\mathrm{pO}_{2}$ level was $2.5 \%$ PAL (present atmospheric level), thus geological evidence is used to rule out (or falsify) $\mathrm{pO}_{2}$ levels > $10 \%$ PAL or $<0.1 \%$ PAL, hence constraining $\mathrm{pO}_{2}$ levels at $0.1-\%$ PAL. Similarly, Chen et al. (2014) provide evidence against the phylogenetic interpretations of Megasphaera as a Thiomargarita-like bacterium (Bailey et al., 2007; but see Xiao et al., 2007b), a mesomycetozoean-like holozoan (Huldtgren et al., 2011; but see 
Schiffbauer et al., 2012 and Xiao et al., 2012), a unicellular protist (Bengtson et al., 2012), or a Volvox-like alga (Xue et al., 1995; but see Xiao and Knoll, 1999). Thus, the surviving hypotheses - a stem-group metazoan or a multicellular alga (although not Volvox) - warrant further consideration. Hence, Tang's "alternative" phylogenetic interpretation is one of the two hypotheses acknowledged in Chen et al. (2014) and currently being evaluated by Doushantuo workers.

Among the two surviving hypotheses, we feel that the multicellular algal interpretation is unsatisfactory because, unlike the stem-group metazoan hypothesis, it is not a precisely defined phylogenetic interpretation. Multicellular algae include members of chlorophytes, rhodophytes, and phaeophytes, and they are a polyphyletic group with few uniting features. As a result, this hypothesis does not make specific predictions that are testable against the fossil record, and it is almost impossible to falsify. In considering the possibility of an algal interpretation for Megasphaera, we strongly urge Doushantuo workers to focus on precisely defined phylogenetic interpretations such as the corallinophycidean hypothesis (Xiao et al., 2004, 2014a) or the Volvox hypothesis (Xue et al., 1995), and to evaluate the possible linkage among Megasphaera, Wengania, Thallophyca, and other related fossils from the Doushantuo Formation. Likewise, in assessing an animal interpretation, a critical examination of the relationship among Megasphaera, Helicoforamina, Spiralicellula, Caveasphaera, Eocyathispongia, and various tubular fossils may be profitable (Xiao et al., 2007a; Cunningham et al., 2015; Yin et al., 2015). Such analyses would ultimately lead to a more complete understanding of Megasphaera's life cycle, which is a key to constraining its phylogenetic affinity.

Tang (2015) argues that the matryoshkas in Megaclonophycus-like fossils may have been parasites or symbionts, a hypothesis that has been considered and rejected by Chen et al. (2014). Chen et al. (2014) illustrated a series of specimens, including one-cell stage, Parapandorina-stage, Megaclonophycus-stage, and matryoshka-stage 
specimens, and interpreted them as representing a sequence of ontogenetic stages of Megasphaera. The ontogenetic sequence from one-celled to Parapandorina-stage to Megaclonophycus-stage fossils of Megasphaera has been well established and widely accepted. The new discovery of Megaclonophycus-like fossils with dyads/tetrads and Megaclonophycus-like fossils with matryoshkas allows Chen et al. (2014) to extend the ontogenetic sequence to include the matryoshka-stage fossils, because - other than the presence of dyads, tetrads, and matryoshkas — these fossils are very similar to Megaclonophycus-stage fossils in cell division patterns and being enclosed within an ornamented envelope. Tang (2015) questions this interpretation because cell division is palintomic in Megaclonophycus-stage fossils but not so in matryoshka-stage fossils. "Although it is possible that at some point the mode of division is switched (presumably with a slowing down of the cell cycle transition and a longer inter-phase to allow cytoplasmic growth), how the encasing envelope is made during such a switch could not be envisaged from the features presented", Tang (2015) writes. Here, Tang (2015) misrepresents the matryoshkas as structures encased in an ornamented envelope (he also writes "these matryoshka cells remained encased in an ornamented envelop [sic]" and mentions "the encased and closely sutured feature of the cells of the matryoshkas"; italics ours); it is clear from Chen et al.'s (2014) description and illustration that the matryoshkas are not encased in an ornamented envelope. More importantly, we would like to point out that a switch away from palintomy is not just a possibility but a necessity, because indefinite palintomy is physically unsustainable. Any organisms that are engaged in palintomy must switch out of this mode of cell division at some point of their life cycle in order to restore cell size and to avoid approaching a cell size of zero. Thus, a change in cell division mode between Megaclonophycus-stage cells and matryoshka cells is not a valid argument against their ontogenetic continuity.

As another piece of evidence against an ontogenetic continuity between 
Megaclonophycus-stage and matryoshka-stage fossils, Tang (2015) points out that the former appears to be engaged in rapid cell division, with dyads being a frequent feature, whereas the latter appears to consist of largely interphase-like cells. His observation is largely accurate, although dyads do occur in some matryoshka-stage fossils (e.g., fig. 3e of Chen et al., 2014). However, this observation is consistent with a change from rapid palintomy in Megaclonophycus-stage to slow cell division in matryoshka-stage, possibly with a longer inter-phase in the latter as surmised by Tang (2015). As we argue above, this switch is an ontogenetic necessity of palintomic organisms, and not evidence against developmental continuity between Megaclonophycus-stage and matryoshka-stage fossils.

As additional evidence, Tang (2015) states that "the encased and closely sutured feature of the cells of the matryoshkas makes these appear more similar to whole organisms rather than a bunch of loose gametocytes that are readily dispersed upon release." As mentioned above, the matryoshkas are not encased within an ornamented envelope (Chen et al., 2014). Also, Chen et al. (2014) interpreted the matryoshkas as asexual reproductive structures, rather than sexual gametangia, although we admit that the function of the matryoshkas as sexual or asexual reproductive structures is still uncertain. Nonetheless, in the spirit of invoking further discussion, we would like to point out that, in addition to rhodophytes (Xiao et al., 2004), many sponge animals (some of which lack an aquiferous system) also have asexual gemmules and sexual gametangia (Riesgo et al., 2007; Bautista-Guerrero et al., 2010; Chu and Reiswig, 2014) that are at least broadly similar to the matryoshkas.

Finally, Tang (2015) points out that "there appear to be fully matured Megaclonophycus-stage spheroids that are devoid of any matryoshka", citing thin-section light microscopic images published in Chen et al. (2014). Tang (2015) regards this as evidence consistent with matryoshkas being parasites or symbionts, rather than representing part of the ontogenetic sequence of Megasphaera. 
Presumably, Tang (2015) determines maturity on the basis of cell size, assuming that palintomy continues throughout Megaclonophycus- and matryoshka-stages. This is a problematic assumption (see above discussion on switch of cell division modes; also see Extended Data fig. 1b of Chen et al., 2014). In addition, thin sectioning is not a safe technique to confirm the lack of matryoshkas, which may be missed in any particular cuts.

In summary, with available evidence, the matryoshkas likely represent an ontogenetic stage of Megasphaera, rather than parasites or symbionts. Accepting this ontogenetic interpretation, it follows naturally that the differentiation and growth of matryoshkas within a Megasphaera spheroid of constant size requires programmed cell death. Tang (2015) emphasizes the demonstration of the activation of caspase cascades as a proof of apoptosis, but this biochemical pathway is unlikely to leave any detectable trace in the fossil record. Tang (2015) also states that "programmed cell death is not restricted to metazoans, and components of cell death machineries are known to be encoded in the genome of their closest unicellular relatives". Although this statement is true, we emphasize that the fossils speak to the phenotype of programmed cell death, which does not occur in unicellular organisms even if they might have components of the genetic machineries for apoptosis. To draw an analogy, the last common ancestor of bilaterians likely possessed components of the genetic machineries for segmentation and limb formation (De Robertis, 1997), but that does not necessarily mean that it was a segmented and legged animal (Hannibal and Patel, 2013).

If the matryoshkas eventually turn out to be parasites or symbionts, then they would have no phylogenetic implications for Megasphaera - one way or the other, given that parasites or symbionts are widely present in a wide range of multicellular algae and animals (particularly lower animals such as sponges and cnidarians). We would then go back to the drawing board with regard to the life cycle of Megasphaera 
(Xiao et al., 1998).

\section{Acknowledgements}

We would like to acknowledge the support through research grants from the Chinese Ministry of Science and Technology (2013CB835000), National Natural Science Foundation of China (41130209), Chinese Academy of Sciences (KZZD-EW-02), National Science Foundation Sedimentary Geology and Paleobiology Program (EAR-1250800, 1528553), NASA Exobiology Program (NNX15AL27G), and Shandong University of Science and Technology (0104060510311).

\section{References}

Bailey, J.V., Joye, S.B., Kalanetra, K.M., Flood, B.E., Corsetti, F.A., 2007. Evidence of giant sulphur bacteria in Neoproterozoic phosphorites. Nature 445, 198-201.

Bautista-Guerrero, E., Carballo, J.L., Maldonado, M., 2010. Reproductive cycle of the coral-excavating sponge Thoosa mismalolli (Clionaidae) from Mexican Pacific coral reefs. Invertebrate Biology 129, 285-296.

Bengtson, S., Cunningham, J.A., Yin, C.Y., Donoghue, P.C.J., 2012. A merciful death for the "earliest bilaterian," Vernanimalcula. Evolution \& Development 14, $421-427$.

Chen, L., Xiao, S., Pang, K., Zhou, C.M., Yuan, X.L., 2014. Cell differentiation and germ-soma separation in Ediacaran animal embryo-like fossils. Nature 516, $238-241$.

Chu, J.W.F., Reiswig, H.M., 2014. Mechanisms of propagule release in the 
carnivorous sponge Asbestopluma occidentalis. Invertebrate Biology 133, $109-120$.

Cunningham, J.A., Vargas, K., Liu, P.J., Belivanova, V., Marone, F., Martínez-Pérez, C., Guizar-Sicairos, M., Holler, M., Bengtson, S., Donoghue, P.C.J., 2015. Critical appraisal of tubular putative eumetazoans from the Ediacaran Weng'an Doushantuo biota. Proceedings of the Royal Society B: Biological Sciences 282, doi: 10.1098/rspb.2015.1169.

De Robertis, E.M., 1997. The ancestry of segmentation. Nature 387, 25-26.

Hannibal, R.L., Patel, N.H., 2013. What is a segment? EvoDevo 4, doi: 10.1186/2041-9139-1184-1135.

Huldtgren, T., Cunningham, J.A., Yin, C.Y., Stampanoni, M., Marone, F., Donoghue, P.C.J., Bengtson, S., 2011. Fossilized nuclei and germination structures identify Ediacaran "animal embryos" as encysting protists. Science 334, 1696-1699.

Riesgo, A., Taylor, C., Leys, S.P., 2007. Reproduction in a carnivorous sponge: the significance of the absence of an aquiferous system to the sponge body plan. Evolution \& Development 9, 618-630.

Schiffbauer, J.D., Xiao, S., Sen Sharma, K., Wang, G., 2012. The origin of intracellular structures in Ediacaran metazoan embryos. Geology 40, 223-226.

Tang, B.L., 2015. Are the new Ediacaran Doushantuo Megasphaera-like acritarchs early metazoans? Palaeoworld, doi: 10.1016/j.palwor.2015.06.005.

Xiao, S., Knoll, A.H., 1999. Embryos or algae? A reply. Acta Micropalaeontologica Sinica 16, 313-323.

Xiao, S., Zhang, Y., Knoll, A.H., 1998. Three-dimensional preservation of algae and 
animal embryos in a Neoproterozoic phosphorite. Nature 391, 553-558.

Xiao, S., Knoll, A.H., Yuan, X.L., Pueschel, C.M., 2004. Phosphatized multicellular algae in the Neoproterozoic Doushantuo Formation, China, and the early evolution of florideophyte red algae. American Journal of Botany 91, 214-227.

Xiao, S., Hagadorn, J.W., Zhou, C.M., Yuan, X.L., 2007a. Rare helical spheroidal fossils from the Doushantuo Lagerstätte: Ediacaran animal embryos come of age? Geology 35, 115-118.

Xiao, S., Zhou, C.M., Yuan, X.L., 2007b. Undressing and redressing Ediacaran embryos. Nature 446, E9-E10.

Xiao, S., Knoll, A.H., Schiffbauer, J.D., Zhou, C.M., Yuan, X.L., 2012. Comment on "Fossilized nuclei and germination structures identify Ediacaran 'animal embryos' as encysting protists". Science 335, 1169c.

Xiao, S., Muscente, A.D., Chen, L., Zhou, C.M., Schiffbauer, J.D., Wood, A.D., Polys, N.F., Yuan, X.L., 2014a. The Weng'an biota and the Ediacaran radiation of multicellular eukaryotes. National Science Review 1, 498-520.

Xiao, S., Zhou, C.M., Liu, P.J., Wang, D., Yuan, X.L., 2014b. Phosphatized acanthomorphic acritarchs and related microfossils from the Ediacaran Doushantuo Formation at Weng'an (South China) and their implications for biostratigraphic correlation. Journal of Paleontology 88, 1-67.

Xue, Y.S., Tang, T.F., Yu, C.L., Zhou, C.M., 1995. Large spheroidal chlorophyta fossils from the Doushantuo Formation phosphoric sequence (late Sinian), central Guizhou, South China. Acta Palaeontologica Sinica 34, 688-706 (in Chinese, with English summary). 
Yin, Z.J., Zhu, M.Y., Davidson, E.H., Bottjer, D.J., Zhao, F.C., Tafforeau, P., 2015. Sponge grade body fossil with cellular resolution dating 60 Myr before the Cambrian. Proceedings of the National Academy of Sciences of the United State of America 112 (12), E1453-E1460, doi: 10.1073/pnas.1414577112. 